\title{
Nanotube Sheet and Yarn Manufacturing and Commercialization
}

\author{
MARK J. SCHULZ, SUNG YONG KIM, ASHLEY KUBLEY, DAVID MAST, VESSELIN SHANOV \\ College of Engineering and Applied Sciences \\ Nanoworld Laboratories, University of Cincinnati, Cincinnati, Ohio 45221, USA
}

\begin{abstract}
Nanotube macroscale materials such as yarns, tapes, and sheets provide combinations of material properties that are unique relative to existing materials. Although nanotube sheet and yarn commercialization is still an emerging activity, these materials may become important in the future Business and Economics of societies. Therefore, this paper surveys current worldwide efforts toward manufacturing and commercialization of nanotube macroscale materials. The survey will help researchers, investors and economists consider how the new materials might be used in new applications and how the materials might spur economic development. Nanotube macroscale materials consist of yarn, tapes, and sheets, and exclude powdered forms of nanotubes used as filler materials. Both Carbon Nanotube (CNT) and Boron Nitride Nanotube (BNNT) materials are considered. It is anticipated that macroscale sheet and yarn with customizable properties will have broad applications. This paper is organized to provide ideas for possible areas of applications of nanotube yarn and sheet, followed by a survey of current commercialization efforts. Manufacturing barriers that must be overcome to push the development of nanotube macroscale materials toward large scale commercialization are also discussed. The paper also provides references for researchers and industry professionals who may want to further develop and put nanotube macroscale materials into their own applications.
\end{abstract}

Key-Words: Nanotube, macroscale sheet and yarn, manufacturing, commercialization, applications, economics

Received: December 4, 2020. Revised: July 18, 2021. Accepted: July 31, 2021. Published: August 5,

2021.

\section{Nanotube Emergent Materials}

Nanotubes are perhaps the most well-known material of the nanotechnology revolution [1-55]. Historically, the genesis of nanotechnology occurred internationally in about the 1990's built on the discoveries of many pioneers and supporters of nanotechnology such as Richard Feynman, Millie Dresselhaus, Richard Smalley, Alan Windle, Carlo Montemagno and many others worldwide. A significant milestone occurred in the United States when Mihail C. Roco of the National Science Foundation proposed a National Nanotechnology Initiative (NNI) in 1999. President Bill Clinton then advocated nanotechnology development and first funded the NNI in 2001. The NNI of the United States is now a coordinated Federal program with 20 participating agencies to promote nanotechnology $\mathrm{R} \& \mathrm{D}$. The NNI agencies work together to achieve a vision of "a future in which the ability to understand and control matter at the nanoscale leads to a revolution in technology and industry that benefits society." The 2021 US Federal Budget provides more than $\$ 1.7$ billion for the NNI [56]. Similar examples of nanotechnology initiatives are in the European Union, UK, China, Taiwan, Germany, Mexico, Israel, India, Korea, and other countries.

Nanotechnology encompasses many types of materials with properties that are special due to the small size of the material. There are extensive applications of nanoscale materials. An example is carbon nanotubes (CNTs) and their different material forms (powders and macroscale materials such as yarn and sheet) which are gradually being brought into common use. Powder nanotubes are dispersed and ideally disaggregated within a polymer or elastomer, or some other matrix material. Oppositely, macroscale nanotube yarn and sheet materials are assemblages of nanotubes. Nanotube powder reinforced materials or nanocomposites have been in use for over a decade and the technology is comparatively mature. Thus, powder nanotubes are not surveyed in this article.

Single CNTs have exceptional properties. But assemblages of CNTs that form macroscale fabric, yarn and tape have much lower properties compared to single CNTs. Macroscale forms of CNT materials are expensive to fabricate because the manufacturing 
rate of the nanotube synthesis process is low. In addition, current methods to assemble CNT into large scale materials such as fabric during the synthesis process or by post-processing is a slow and expensive process. The limitations in scaling up properties, and the high cost and complicated manufacturing of nanotubes are holding back some of the potential outcomes of the NNI. Two principal roadblocks to putting CNT macroscale materials into widespread applications are: (i) improving the properties of macroscale materials, and (ii) scalingup manufacturing throughput to lower costs. Overcoming these barriers should be a goal for future R\&D efforts. Boron Nitride (BNNT) materials have similar problems as CNTs in scaling up the properties to form macroscale materials. The limitations and potential of nanotube macroscale materials are discussed in this paper.

\section{Nanotube Manufacturing Barriers}

CNT sheet and yarn materials are manufactured [1] by four primary processes: (i) buckypaper, which starts with powder CNT, then uses liquid dispersion and vacuum to form nonwoven sheet which is modest cost, scalable to large rates of production, and has good electrical conductivity and modest strength; (ii) forest growth, of CNT on substrates and drawing the dry forest to form sheet or drawing and twisting to form yarn produces high purity material with good strength and conductivity, but the batch process is high cost; (iii) floating catalyst, a continuous process that produces a web or sock of CNT that can be wrapped to form sheet or pulled and twisted to form yarn with good conductivity and strength, but the process yield is low; and (iv) acid extrusion, where CNT powder is dispersed in super acid to form yarn with high electrical conductivity and modest strength. Modified floating catalyst materials are also being developed that integrate powder nanoparticles (NPs) into CNT sheet. These are called Carbon Hybrid Materials (CHM). In $\mathrm{CHM}$, metal or ceramic nano or microscale particles are injected into the CNT synthesis process and may chemically react with the CNT, depending on the type of NP [1,2]. Many types of NPs can be integrated into the CNT sheet.

BNNTs are structural analogues of CNTs, where each carbon-carbon atom pair in the hexagonal lattice is replaced by a boron-nitrogen atom pair [1,
Ch. 5]. The bond strengths and the geometric unit cells are closely equivalent for both types of nanotubes. However, the $\mathrm{BN}$ bond is partially ionic and BNNTs show different electron-density distributions in comparison with CNTs [1, Ch. 5]. BNNTs have high strength and low density like CNTs, but BNNTs are not electrically conductive. BNNTs also have exceptionally high thermal stability, high electrical insulation, high neutron absorption, piezoelectricity in bundles, and transparency in the visible region. BNNT are grown generally as a powder not as forests. BNNT can form buckypaper. There is also the possibility to form continuous BNNT sheet and yarn in the floating catalyst method [11].

\subsection{Nanotube Synthesis Barriers}

Barriers holding back large-scale manufacturing and application of nanotubes that are produced using different techniques are briefly discussed. The barriers are mainly engineering problems that can be overcome with continued R\&D. Synthesis of different types of CNTs occurs at different temperatures. Substrate growth of nanotube forests occurs at $800{ }^{\circ} \mathrm{C}$ [8]. Floating catalyst growth of nanotubes that assemble into a web or sock occurs at $1420{ }^{\circ} \mathrm{C}$ [3]. Arc discharge production of nanotubes occurs at $3000{ }^{\circ} \mathrm{C}$. Properties of the synthesized CNT materials depend on the specific process and parameters. For example, in the substrate growth method, the synthesis time can be 15 minutes where in arc discharge/laser ablation the growth time is milliseconds. Thus, different physical and chemical processes and barriers are associated with the different methods to synthesize and to assemble the nanotubes into macroscale forms.

A barrier for all methods is that very long highquality CNT are not available in large quantities to form sheet and yarn [see 1, Chapter 7, Understanding the Direct Spinning of CNT Fibers in Terms of the Thermodynamic and Kinetic Landscape: A Personal View by Alan Windle]. A long sought-after goal is to grow $\mathrm{cm}$ long or longer CNT that are high quality. Forests $2 \mathrm{~cm}$ long and bundles $50 \mathrm{~cm}$ long have been grown but the forests take a long time to grow, and the quality is reduced, and the bundles synthesis method needs to be scaled to large production. All the barriers mentioned seem to be engineering problems, they are not violating physics barriers. Therefore, the dream of researchers is to produce nanotube sheet and yarn in industrial 
quantities. In the future, because of the simpler synthesis methods, CNT may become cost competitive with carbon fibers, which are complicated to produce. The common synthesis methods are briefly discussed with their advantages and limitations.

Buckypaper. Assembling powder nanotubes to form buckypaper in a paper making process may be the lowest cost and most scalable process currently to make CNT sheet. Nanotubes used to form buckypaper can be produced by arc discharge in large quantity, but the nanotubes are short. Buckypaper has good electrical conductivity, but lower strength compared to sheet formed using the floating catalyst method. Polymers may be used to increase the strength of buckypaper. Single wall carbon nanotubes (SWCNT) and multi-wall carbon nanotubes (MWCNT) are both used to form buckypaper.

Forest growth Nanotubes. The substrate method uses a catalyst film on a silicon wafer substrate. The catalyst is annealed in hydrogen gas at the beginning of the synthesis to return the catalyst ( $\mathrm{Fe}$ or alloy of $\mathrm{Fe})$ to the pure metal state. The wafer templates the growth of a forest of CNTs. Typically, a spinable forest is $1 / 2$ or $1 \mathrm{~mm}$ long where the CNT have a few walls. Cost of the substrate and time required for the batch process limit the scale up of manufacturing. Automated wafer loading and synthesis in a coldwall plasma enhanced CVD reactor can improve throughput. Spinning CNT yarn under a microscope provides high properties but the method is not scalable [52]. A barrier with forest grown CNT that are used for winding sheet or spinning thread has been the nanotubes are relatively short, perhaps 1 $\mathrm{mm}$ long. Longer forests can be grown but the spinability and quality decrease with length. Also, the spinable forests typically have wavy multi-wall CNTs that have a lower Raman G/D ratio (about 2) than powder SWCNT grown using arc discharge or different methods which have G/D ratios of 20 or higher.

Floating catalyst nanotube Yarn and Sheet. Continuous synthesis using the floating catalyst method may reduce the cost of nanotube materials compared to batch processing by the substrate method. The floating catalyst method is a gas phase pyrolysis technique for CNT growth in a continuously running process. A carbon source is injected at the inlet of the ceramic tube furnace. The synthesized CNT web or sock is collected at the outlet end of the furnace. The sock can be wound onto a drum to form sheet or tape, or a yarn if twisted. The fuel or feedstock is composed of a metal catalyst (Fe [3], Ni [4] or Co [5]). The carbon source is a hydrocarbon (alcohol or gas). Sulfur is a growth promoter. Carrier gases such as hydrogen, argon, helium, nitrogen or a mixture of two or more of these gases enable atomizing the feedstock and carrying the metal catalyst into the furnace. The ceramic tube in the furnace has a vertical or horizontal orientation, or in between [6-8]. In the floating catalyst method, the dwell time of the CNT in the reactor is only about 5 seconds. CNT fabric is a nonwoven material. Therefore, it is much simpler to manufacture than woven or knitted fabrics. CNT yarn can be woven to form stronger fabric. The limitation is the cost of CNT yarn is higher than sheet. The weaving process increases cost. The properties of CNT fabric and yarn vary depending on the exact manufacturing conditions. The properties of macroscale CNT sheet and yarn are satisfactory for certain applications. However, increasing the properties has been a long-standing goal to access more applications and to be more competitive with existing fibers and textiles. The sock produced in the floating catalyst reactor tube is wound onto a drum at the outlet of the reactor. Modifying the flow can affect how the sock is formed and improve the synthesis process. Axial backflow and circumferential flow can be modified by the configuration of the inlet and the way gases are injected. The benefits are to make a stronger sock and stronger more conductive yarn or sheet. Flow control might customize the material and change the isotropy of the pre-control material. The typical method of synthesis is to put reactants in the inlet of the ceramic tube and collect the product at the outlet of the reactor tube. Presently, flow control is being used to increase the throughput of the process. Also, the plasma formed when using Ar as the carrier gas, being electrically conductive, can be manipulated by electromagnetic coils and fields.

Metallic Chirality Nanotubes. Advances have been made in synthesis of mostly metallic armchair nanotubes with improved electrical conductivity. Metallic Quantum wires are being developed to promote a highly conductive material that can take 
high temperatures during extreme electron emission [11]. Another new material is the CNT-based wire conductor with BNNT non-woven matt used as dielectric insulation in coaxial cables [11]. This design reduces the weight of high frequency electrical conductors.

Carbon Hybrid Materials (CHM). In carbon hybrid materials development, melting point, boiling point, wetting, phase diagrams, and nanoparticle (NP) injection are used to produce designer materials with partially specified properties. Important is to improve control over nucleation, growth and assembly of CNT hybrid materials. NP catalyst type and size affects melting point, reactivity, and other properties, and nanotube length. Scale up reactor development has been a barrier in the field, and may need to be partly financed by industry, along with government agencies. CHM materials properties can be customized based on a specific application. A limitation of these methods is that the production rate of the process is low. Increasing reactor size may reduce the cost of the material for commercialization. A limitation is that large ceramic tubes are expensive and brittle. Therefore, new technology is required to increase the production and decrease the cost of CNT sheet and yarn, see Ch. 7 and Ch. 23 in [1]. Flow control may be a partial solution to scale up as throughput is increased by flow control in a small reactor as opposed to using a large reactor with conventional processing. The floating catalyst method is attractive commercially as it produces CNT sock that is wound on a drum to form sheet or tape, or twisted to form yarn in a nonstop process.

Acid extrusion to form CNT Yarn. In the super acid method, high quality single wall CNTs are extruded from a nozzle to form yarn. The yarn has high electrical conductivity. The acid is dangerous and must be handled using special procedures. Reducing cost is needed to make the electrically conductive CNT yarn affordable for practical applications that require large quantities of material. Cost is not as critical for applications like field emission that do not require as large of quantities of material. Superacid treated CNT are described in [54]. A barrier with superacid CNT is that short nanotubes that are high quality are needed for the process. Longer CNT become tangled and lower quality CNT do not provide good strength and high conductivity in the yarn produced.

BNNT Synthesis. Boron Nitride Nanotubes (BNNT) can be formed using the following methods: pressurized vapor/condenser (PVC), hydrogenassisted synthesis (HABS), Chemical Vapor Deposition (CVD), and Ball milling/annealing [1, Ch 5]. BNNT sheet and yarn materials are in initial stages of R\&D compared to CNT. A novel approach being investigated to grow BNNT is based on the floating catalyst method. The goal is to produce sheet and yarn similar to the way CNT sheet and yarn are produced. Precursors used to form BNNT can be poisonous. Therefore, special precautions are needed to synthesize BNNT.

Long CNT Synthesis. Up to half meter long CNT bundles are being synthesized [53]. If the method can be scaled up, it would revolutionize fiber materials. A moving furnace keeps the synthesis condition constant and the growth going for a long time. Pre-tensioning the fibers in a bundle produces equal load sharing among the CNT and high strength of the bundle. Moving the reactor to maintain the exact growth conditions for precise synthesis are being investigated for the different approached to synthesis CNT.

\subsection{Safety of Nanotube Yarn and Sheet} Commercialization of nanotube fabric and yarn depends on the safety of the material [see 1, Chapter 7]. Safety is discussed on two company web sites. Q Flow in the UK (https://www.q-flo.com/advancedtechnology/) states on their web site; "The high temperature gas phase process produces very long carbon nanotubes, which coalesce to form a continuous aerogel. The aerogel is collected to form the continuous mat. The material is intrinsically safe as the carbon nanotubes, from the point of production, are tightly bound into rope like nanostructures containing 10 to 100 tubes. Monitoring has confirmed that single carbon nanotubes are not released during manufacture or processing." Nanocomp Technologies [10] also considers the nanotube sheet safe; "Nanocomp Technologies is the producer of carbon nanotube-based Miralon $\mathbb{}$ products. Nanocomp's products differ from other carbon nanotube materials because they are macrostructures (articles) and not loose powders (particles). This "article versus particle" distinction has many technical, regulatory, and safety 
advantages that are explained below." The pristine CNT macroscale materials are considered safe when used in composites and in different products depending on the application. CNT contacting the skin, chemically modified CNT materials, and the safety of burning or damaged CNT materials have not been fully characterized for safety. CNT also have not been well characterized for use in the body, although FDA polymers can be used to coat CNT yarn used in the body. It is important to emphasize here that CNT sheets and yarns behave differently compared to powdered CNTs. The van der Walls forces between the tubes in the sheets and yarns, enhanced by solvent densification, minimizes the probability to release airborne CNTs.

BNNT synthesis by CVD uses toxic chemicals such as diborane gas. BNNT are nanoscale materials. In the USA, handling, processing, and transportation of the material must meet all U.S. Department of Transportation (DOT) and U.S. Environmental Protection Agency (EPA) regulations. In an $\mathrm{R} \& \mathrm{D}$ phase, BNNT should be classified as nanomaterials. Researchers should employ safety processes similar to those be used for CNT. An overview of BNNT synthesis and applications is given in [55]. BNNT can also be produced using arc discharge, substitution reaction, and laser ablation methods.

\subsection{Exotic and Extreme Materials Creation}

Exotic and Extreme Materials are sought for use in certain unique and extreme environments and in applications that will transform our lives [57-64]. Singular design and artificial synthesis might produce these new specialized and exotic materials. Development of specific emergent and extreme innovative materials will require using non-standard processing conditions and hybrid synthesis methods. Materials genesis explores new structures and compositions of materials while materials processing explores new multi-physics methods to control and provide hierarchical properties of materials. Background on emergent and extreme materials is given in [65-76]. Materials Scientists and Engineers are now focused on designing new materials and evaluating the performance of the new materials for select applications based on industrial requirements. An example is design of carbon nanotube hybrid materials that combine carbon nanotubes with metals, ceramics, or other carbon materials to form hybrid material forms such as sheets and yarn that have properties and behaviors unlike any existing materials. Developing these exotic materials and "designing in" material functionality provides new enabling properties foundations for all areas of engineering and requires interdisciplinary research. A more fundamental approach to make exotic materials is for scientists to imagine new materials and assemble (model) them on the computer working with molecules and atoms. The book, Made to Measure by Philip Ball, explores Exotic and Extreme Materials Creation. It describes "how scientists are currently inventing thousands of new materials, ranging from synthetic skin, blood, and bone to substances that repair themselves and adapt to their environment, that swell and flex like muscles, that repel any ink or paint, and that capture and store the energy of the Sun." This is accomplished because materials are being "made to measure" and designed for individual applications, instead of being discovered in nature or created by trial-and-error experimentation. The book describes various areas where new materials will transform our lives in the twenty-first century. Material described in the book include smart materials, photonic materials, materials for information storage, biomaterials, biomedical materials, materials for energy storage and clean energy production, porous materials, diamond and hard materials, new polymers, and surfaces and interfaces.

Another approach to form exotic materials is by design of experiments [6]. Modeling certain processes is too complex and scientists must resort to experimentation to understand reactions and to shape new materials. An example is nanotube synthesis. It is not fully understood why the nanotube growth process stops and how to extend the growth. Moreover, it is a mystery exactly how nanotubes self-assemble in the gas phase to form a sock in the floating catalyst method. Through simulation and experimental validation [3] gas flows are being better understood. Now the process is being modified to control the gas flows which in turn affect nanotube assembly into the sock. This is an example of using simple simulation and experimental observation to better understand how to control a nanotube synthesis process and to hybridize the nanotube material to form new exotic materials that are combinations of carbon nanotubes, metals, ceramics, or other carbon nanomaterials. Gas phase assembly and hybridization of nanotubes is an 
emergent area of research and a path to synthesize artificial exotic and extreme materials.

Purification Procedures and Standards. Pristine CNT sheet can contain hydrocarbon by-products, amorphous carbon, and iron catalyst from the synthesis process. The quality of the CNTs produced depends on the process conditions. Using a low flow rate for the fuel for example will produce CNT that have high crystallinity (G/D ratio of 100 using Raman spectroscopy), but the yield of the process is low. A trade-off is to use a moderate flow rate for the fuel that produces good quality CNT and has a satisfactory yield. Purification procedures include wiping the CNT sheet with a solvent like acetone, or cleaning the CNT sheet with acid such as dilute nitric and hydrochloric acid to remove the iron catalyst. Annealing the sheet in air around $400{ }^{\circ} \mathrm{C}$ is a method to remove amorphous carbon and chemical deposits. In the USA, a report on the safety of nanotubes is available [80]. Metrology standards from ISO, NIST, the NRC and other organizations are also available, along with references for CNT safety $[81,82]$.

\section{Applications}

Nanotube development has received commercial success in space and aerospace applications, and certain high value structural and electrical applications [3,4, 12-32, 42]. Material characteristics that provide value include being strong, lightweight, flexible, electrically conductive (CNT) or insulating (BNNT), and chemical \& environmental resistance. Further development and lower cost for nanotube materials would enable expansion into other applications. CNT fabric and yarn applications cover commercial products in the areas of wearables and technical textiles, fashion apparel, medicine, laminated composite materials, electrical power conductors, high frequency electromagnetic shielding materials, carbon layers in clothing, textile heater elements, electrostatic discharge protection, and water, air, and virus filtration [79].

Wearable textiles and consumer apparel applications are described in $[1,14,15]$. Hybrid textiles can be formed by integrating metal, carbon, or ceramic particles into the CNT fabric, as described in [1,15-17]. Tapes and sheets of CNT are used in composite structures [6,18], for detecting delamination damage [19], and health monitoring of structures [20]. CNT materials are also currently used in antenna and communication applications [21-23]. Additionally, CNT energy storage and supercapacitor applications [24-26] are recently increasing. New outcomes of carbon materials hybridization with $2 \mathrm{D}$ materials may be materials that can transform $\mathrm{CO}_{2}$, improve solar cells, and new 1D, 2D, and 3D materials. CNT antennas, batteries, and supercapacitors will be integrated into textiles and consumer apparel. Biosensing is another emerging application [79]. Three areas of emerging applications for CNT bulk materials are shown in Fig-1. Specific application areas are reviewed next.

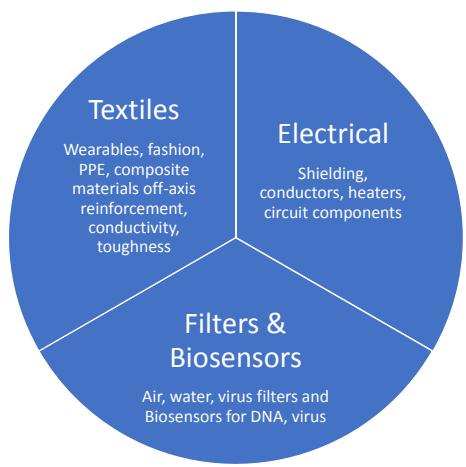

Fig.1: Emerging areas of applications for CNT fabric, tape, and yarn materials.

\subsection{Water and Air Filters}

Heavy metals have a high density relative to water and do not degrade in a natural environment like various organic pollutants [27]. Heavy metals such as $\mathrm{Cd}, \mathrm{Hg}, \mathrm{Ni}, \mathrm{Co}$, and $\mathrm{Pb}$ can be toxic when ingested. $\mathrm{Pb}$ is the most common poisonous metal ion [28]. Industrial activities are the major sources [29] of $\mathrm{Pb} . \mathrm{Pb}$ pollutants are produced from battery manufacturing, acid metal plating and finishing, and tetraethyl lead manufacturing. $\mathrm{Pb}$ damages the kidneys, liver, and nervous and reproductive systems [28]. Thus, it is critical to minimize $\mathrm{Pb}$ contamination to protect society [30]. CNTs is an absorbent (allows gases and liquids to permeate it uniformly) which can remove heavy metals [31] such as lead ions [32] from water. CNT fabric has a large surface area, high porosity, and strong interaction between contaminant molecules. These features make CNT membranes useful for absorption and filtration applications [33-34]. Adsorption properties (a dissolved solid, gas, or liquid adheres to the material surface) of CNT membranes depend on the quality of the fabric, including the purity, 
porosity, surface area, and surface functional groups [33]. Chemical surface functional groups can enhance the adsorption rate of heavy metals [33] onto CNT fabric. Treatment with acids such as $\mathrm{HCl}$, $\mathrm{H}_{2} \mathrm{SO}_{4}, \mathrm{HNO}_{3}, \mathrm{KMnO}_{4}$, and $\mathrm{H}_{2} \mathrm{O}_{2}$ [37] attached different functional groups onto the surface of the CNT membrane. The functional groups remove specific contaminants. Acid treated CNT membranes can have a greater absorption capability than pristine CNT membranes. This is due to the electrostatic interaction between the negative charge on the CNT's surface and the positively charged metal ions [35-36]. CNTs can also have different hydrocarbon contaminants on the surface due to the synthesis process. Acid treatment can remove impurities from the CNTs [33]. CNT fabric can be modified with different types of nanoparticles to improve the removal efficiency of heavy metals. CNT membranes are also being evaluated to remove natural organic matter (NOM) from water. Air filtration is another application area of CNT fabric [see Ch. 26 in 1]. Facemasks [78] are an emerging application to filter air pollution and virus from the air.

\subsection{Electrical Conductors}

The electrical conductivity of $\mathrm{Cu}$ decreases at high temperatures. This makes $\mathrm{Cu}$ undesirable for use in high temperature operation. Copper has a high density $(8.9 \mathrm{~g} / \mathrm{cc})$ [38] which makes it undesirable for flight vehicles. Moreover, at high frequencies $\mathrm{Cu}$ electrical conductors lose effectiveness due to the skin effect. The skin effect effectively reduces the size of the conductor. An advantage of CNT yarn is that is does not lose effectiveness at high frequency, high voltage, and high temperature. This leads to the possibility of $\mathrm{Cu}$ conductors being replaced with CNT conductors for high temperature use. The electrical resistivity of CNT sheets is stable or decreases at higher temperatures. The structure of CNT yarn inherently resembles multi-strand litz wire which is suitable for use at high frequencies without experiencing the skin effect. Another advantage is that CNT has a higher maximum current density than $\mathrm{Cu}$ wire. The density of CNT wire density is $1.4 \mathrm{~g} / \mathrm{cc}$ which is about $1 / 6$ the density of $\mathrm{Cu}$ wire. CNT metal hybrid wire is an option being developed that trades-off density for improved conductivity [11]. On the downside, CNT wire is very high cost and less conductive than $\mathrm{Cu}$. Recent advances suggest that CNT hybrid wire might replace $\mathrm{Cu}$ wire in high value applications [44].

\subsection{Heater Fabric}

Electrically conductive CNT fabric can be incorporated into textiles for heating applications due to the excellent electrical and thermal properties. CNT yarn and tape provide conductive pathways in fabric. Composited materials (containing layers of different fabrics) are used. CNTs also provide large surface area and porosity. Acceptable mechanical properties, light weight, and flexible material provide a practical fabric heater material. Advantages of CNT heater fabric are uniform heating, light weight, and being thin and flexible not adding stiffness or bulk to garments. Heating rate is determined by CNT fabric thickness, length, and applied voltage. The resistivity of CNT fabric can be varied to provide the needed power at the desired voltage level, per $P=V^{2} / R$, where $P=$ power dissipated as heat, $\mathrm{V}=$ applied voltage, and $\mathrm{R}=$ resistance of the fabric. CNT fabric thus also functions as a heater element [15].

\subsection{Technical Textiles}

Layered or composited textiles incorporating a thin CNT layer inside a garment are under development in the areas of functional and smart textiles. CNT fabric, tapes and yarns have a unique set of properties that can extend the capabilities of functional textiles and enable new applications in the consumer, industrial, government, and military markets. CNT fabric provides added capabilities in textiles such as filtration of waterborne and airborne contaminants; heat spreading; electrical conductivity that can support flexible wires and integrated electronic components, and the possibility to harvest power from body motion. Current CNT fabric is lightweight, but the mechanical properties are modest. The potential to harness and store energy using flexible, lightweight power systems would be an enabling advance. CNT fabric is thin and soft and can supplement conventional fabrics without changing the inherent fabric properties like softness and flexibility making it discreet and easily integrated into garment systems. CNT properties area considered additive and can open up new possibilities for the design of consumer-driven smart and technical textiles. Technical textiles can monitor the condition of the body, improve comfort and safety, and improved performance. CNT technical textiles provide an appealing advantage in the 
emergent Smart Textiles and Wearable Technology markets, which are growing rapidly. Performance enhancing CNT materials with sensory, reactive, and self-powered properties define a new class of functional textiles that are active or smart and respond to their environment. CNT multi-functional textiles can be exploited in the apparel, home, occupational, and specialized equipment markets $[16,57]$.

\subsection{Nanotube Composited Clothing}

CNT fabric manufactured using the floating catalyst method has properties that are useful for many applications. Still, to achieve better properties and enable more applications, it is important to integrate nanoparticles or microfibers into CNT fabric. Metal/alloy or other nanoparticles can be integrated into the CNT synthesis process and in the fabric produced. Wetting of carbon with metals and the solubility of carbon in the metal must be taken into consideration [39]. Group VIII metals generally wet CNT's due to the solubility of the solid phase in the liquid phase [40]. Carbide forming metal melts form chemical compounds during the synthesis process and can wet CNTs. On the other hand, high surface tension liquids do not wet the CNT's but can be used to decorate the outer surface of the CNTs [41]. The wetting contact angle and wetting properties also depend on experimental conditions. The advantage of adding nanoparticles or microfibers to form CNT hybrid fabric is to enable customizing the properties of textiles. An example of an application is a firefighter's glove, Fig-2, which has a thin flexible CNT fabric layer that provides heat spreading and flame resistance while adding almost no mass or bulk to the glove.

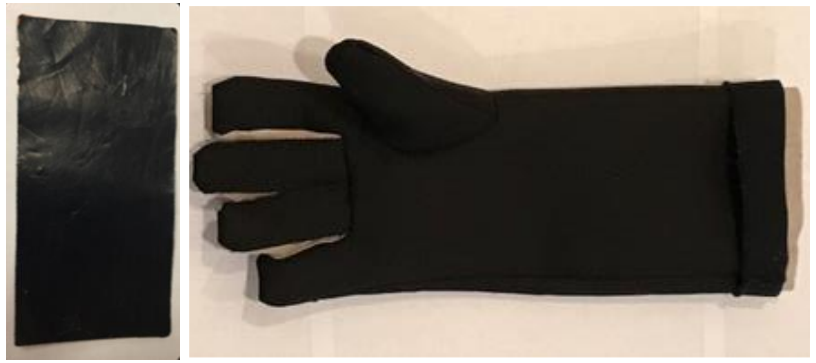

Fig.2: Example application: CNT fabric used as a center layer in a prototype glove for firefighting.

\subsection{Biomedical Wire}

Biomedical wire can be formed using CNT yarn.
CNT yarn wire has been used to cross the skin of mice to connect to sensors. Other possible applications are to transmit power from a battery to a biodegradable implant, and as a linear scaffold to regenerate damaged neurons [1, Ch 31]. Further biomedical applications that can be imagined include reinforcing bone, powering robots, pacemaker wire, and others. CNT biomedical wire is flexible and soft and can replace metal wire to transmit power or to communicate with devices implanted inside the body. CNT wire from inside the body can cross the skin and connect to technical textile apparel to monitor and record information about the physiological condition of the body. CNT wire may also be used as micro-electrodes and receive signals from neurons in the body and transfer the signals to wearable electronics in technical textiles to diagnose or treat different medical conditions. The medical devices described require interdisciplinary research efforts and time to fully develop.

\section{Commercialization}

While there are thousands of companies worldwide working with nanoscale materials, and hundreds of companies worldwide working with powder CNTs, the number of companies developing fabric and yarn is perhaps in the tens. Table 1 is a list of some of companies manufacturing and commercializing CNT and BNNT fabric and yarn. A few companies in the USA are [9-12]. Other companies are using the fabric for applications such as electrical shielding of cables [13]. Unintentionally, some companies will not be listed due to limitations in the literature review. The authors apologize for any companies that have been missed and are not listed in this review.

In the long term, investment in CNT fabric and yarn will be sensible commercially in various areas. Advances have been coming in CNT manufacturing from various research laboratories around the world. Synthesis of bundles of half-meter long CNT (Tsinghua Univ., China), carbon nanotube hybrid materials (USA), control of chirality to produce mostly metallic CNT (IP in work reported in USA, UK, and India), high quality CNT with a high Raman G/D ratio (USA, UK), and high strength for thin sheets of CNT (China, Singapore) have been reported recently. Societal, intellectual, and equipment capital all play into an investment 
strategy. Overall, the low yield and modest strength properties of CNT fabric are a main barriers to be overcome. The current cost of CNT fabric varies greatly depending on the processing method, but it is on the order of a few thousand dollars per pound. The need for development of larger reactors, including simulation, experimentation, and prototyping, requires large investment possibly beyond the level of university research laboratories. The properties of CNT fabric and yarn are anticipated to continue to improve through the efforts of the many research laboratories internationally, but the research findings must be integrated to take advantage of all the advances. In summary, convergence of research findings and efforts, and significant capital investment in scale-up of manufacturing may bring new CNT fabric into mainstream commercial textile and other uses. Companies manufacturing and commercializing nanotube sheet and yarn are typically less than 10 years old. Information in Table 1 was obtained from open sources.

As a benchmark for comparison, the powder form of nanotubes has been used in applications for a couple of decades. Macro scale nanotube materials are still an emerging technology and will have a distinct and separate marketplace compared to powder nanomaterials. Carbon fibers took 50 years of development to find widespread applications. CNT materials have been in development about half that time. Macroscale yarn and sheet can provide improved properties relative to powder nanotubes in many applications such as improving the properties of composite materials. Nanotube fabric and yarn can be formed in a one-step process (floating catalyst) and if the process can be scaled up, CNT sheet and yarn may compete with the carbon fiber market. Carbon fibers are extruded from a die and the fibers must be woven to form sheet. Carbon fibers are very strong and continuous and do not need to be twisted to form yarn.

Table 1. Companies Manufacturing Nanotube Sheet or Yarn.

\begin{tabular}{|c|c|c|}
\hline Company & Information & Products \\
\hline $\begin{array}{l}\text { Adnano technologies } \\
\text { pvt. ltd }\end{array}$ & $\begin{array}{l}\text { Founded in 2013, Ad-Nano } \\
\text { Technologies Pvt Ltd develops } \\
\text { and manufactures nano materials, } \\
\text { conductive nano inks and nano } \\
\text { coatings. Shimoga, India. }\end{array}$ & $\begin{array}{l}\text { Provides nano materials including ultra pure small diameter } \\
\text { single walled carbon nanotubes, metallic \& semiconducting } \\
\text { SWCNT. }\end{array}$ \\
\hline $\begin{array}{l}\text { American Boronite } \\
\text { Company }\end{array}$ & $\begin{array}{l}\text { Founded by David Lashmore, } \\
\text { affiliated with University of New } \\
\text { Hampshire, } \\
\text { http://www.boronite.com/\#!/home }\end{array}$ & $\begin{array}{l}\text { CNT tapes and yarn, BBNT materials, floating catalyst reactors, } \\
\text { extreme environments such as space, single and multijunction } \\
\text { solar cells, electrical conductors, thermal conductors, structural } \\
\text { health monitoring, reinforcement, structural composites, } \\
\text { shielding, ballistic protection, thermal management, radiation } \\
\text { protection, actuation. If safety is confirmed in-vivo, this would } \\
\text { lead to a host of biomedical and environmental applications. }\end{array}$ \\
\hline BNNT LLC & http://www.bnnt.com & $\begin{array}{l}\text { Proposed applications in Biomedical, Ceramic Composites, } \\
\text { Electrical Insulation, Fire Retardant Cabling, Piezoelectrics, } \\
\text { Polymer Composites, Radiation Shielding [43]. }\end{array}$ \\
\hline Dexmat & $\begin{array}{l}\text { Affiliated with Rice University; } \\
\text { https://dexmat.com/ }\end{array}$ & $\begin{array}{l}\text { CNT yarn electrical conductors based on the superacid solution- } \\
\text { processing technology extrusion method for powder CNT; the } \\
\text { highest electrical conductivity CNT material at high cost. }\end{array}$ \\
\hline Fujitsu Laboratories & $\begin{array}{l}\text { https://www.fujitsu.com/global/ab } \\
\text { out/resources/news/press- } \\
\text { releases/2017/1130-01.html, Japan }\end{array}$ & CNT sheets for heat dissipation in electronics \\
\hline $\begin{array}{l}\text { General Nano } \\
\text { Company }\end{array}$ & $\begin{array}{l}\text { https://www.veelotech.com/; spun } \\
\text { off from the University of } \\
\text { Cincinnati }\end{array}$ & $\begin{array}{l}\text { CNT powder nanotubes used to form buckypaper in a large } \\
\text { scale paper like making process, low cost sheet with good } \\
\text { electrical conductivity and modest strength }\end{array}$ \\
\hline $\begin{array}{l}\text { Lintec Company, } \\
\text { Nano-Science \& } \\
\text { Technology Center }\end{array}$ & $\begin{array}{l}\text { http://www.lintec-global.com/; } \\
\text { http://www.lintec-nstc.com/; based } \\
\text { on technology from UT Dallas, } \\
\text { Ray Baughman lab }\end{array}$ & $\begin{array}{l}\text { CNT forests are drawn into sheets and twisted into yarn, } \\
\text { substrate grown CNT, R\&D of carbon nanotube sheets and } \\
\text { others }\end{array}$ \\
\hline $\begin{array}{l}\text { NAiEEL } \\
\text { Technology }\end{array}$ & http://www.naieel.com/naieel/ & Korea Co., Energy and Environmental leading Technology \\
\hline $\begin{array}{l}\text { Nanocomp } \\
\text { Technologies }\end{array}$ & $\begin{array}{l}\text { http://www.miralon.com/; started } \\
\text { by David Lashmore; acquired by }\end{array}$ & $\begin{array}{l}\text { CNT yarn and sheet, and pellets for filler material, based on the } \\
\text { floating catalyst method }\end{array}$ \\
\hline
\end{tabular}




\begin{tabular}{|c|c|c|}
\hline & $\begin{array}{l}\text { Huntsman, a large chemical } \\
\text { company. }\end{array}$ & \\
\hline Nano Mech & $\begin{array}{l}\text { http://www.nanomech.com/nano- } \\
\text { innovations/markets-applications/ }\end{array}$ & Coatings, lubricants, polymer films using nanoparticles \\
\hline Nanointegris & $\begin{array}{l}\text { http://nanointegris.com/our- } \\
\text { products/boron-nitride-nanotubes- } \\
\text { purified-bnnt-p/; }\end{array}$ & $\begin{array}{l}\text { Printing transistors, the next frontier in wearable and flexible } \\
\text { electronics, thin film transistor package with dielectric ink }\end{array}$ \\
\hline Q Flow & $\begin{array}{l}\text { https://www.q-flo.com/; } \\
\text { Technology is from University of } \\
\text { Cambridge, UK }\end{array}$ & CNT yarn and sheet based on the floating catalyst method \\
\hline $\begin{array}{l}\text { Tekna (BNNT-R), } \\
\text { Tekna (BNNT-P and } \\
\text { BNNT-BP) }\end{array}$ & $\begin{array}{l}\text { http://www.tekna.com; } \\
\text { http://www.tekna.com/boron- } \\
\text { nitride-nanotubes }\end{array}$ & $\begin{array}{l}\text { Induction plasma, forming nanoparticles, additive } \\
\text { manufacturing, hot pressing, BNNT buckypaper, anti-radiation, } \\
\text { heat resistant, piezoelectric }\end{array}$ \\
\hline
\end{tabular}

\subsection{Convergence of Academic, Corporate and Clinical Research}

Convergence of academic, corporate, and clinical research and technology commercialization is a new goal to holistically converge University and Community (Next Lives Here and Communiversity courses) efforts to benefit society economically and socially [58]. Many of the companies listed in Table 1 that are commercializing nanotube materials were borne out of Universities. These companies rely on faculty members for technical direction, and many former research students are working at or running the companies. The faculty members and former students in many cases have financial interest in the companies. The new paradigm is for faculty to help create spinoff companies, providing scientific guidance, and receiving financial interest in the company. University policies and government rules guide what the faculty members are allowed to do. Faculty members typically file a Conflict of Interest (COI) plan yearly that must be approved by their department heads, the dean of their college, and the University committee on faculty guidance.

In the past, there was resistance at Universities to allow faculty members to become involved in commercializing their research. The new trend at Universities is to support translation of research to industry to provide near term return on taxpayer's investments. Accelerator programs, Venture Labs, Entrepreneurs-in-Residence and I-Corps [59] programs have sprung up all over to push commercialization of university discoveries. This convergence is helping universities to work at the speed of industry to more quickly generate inventions and to put them into use. Niche conferences are also springing up all over the globe to help develop and industrialize the research from universities in specific areas. In the nanotube field, a few conferences of note are: Guadalupe Workshop on single wall carbon nanotubes \& related materials [60], and the Nanotechnology Materials and Devices (NMD) Workshop ]61], the International Conference on the Science and Application of Nanotubes [62], International Nanotechnology Exhibition and Conference, Japan [63], and the Nanoinnovations Conference [64].

CNT Manufacturers and Suppliers are listed in [83]. The US National Nanotechnology Initiative (NNI) Published a Report on Carbon Nanotube (CNT) Commercialization, March 12, 2015 [84].

\section{Conclusions}

The technology to upscale the properties of nanotubes to the macroscale and to increase the manufacturing yield and reduce the cost of nanotube yarn and fabric are improving and pushing nanotube materials closer to pervasive commercialization. Materials such as carbon fiber and plastics typically take 20-50 years to bring to mass production and commercialization. The nanotube field is about 28 years old. As advances in growing long nanotubes, controlling chirality, and increasing the yield occur, CNT and BNNT sheet and yarn materials will come into more and more applications. Other types of nanotubes and nanowires exist, such as $\mathrm{Fe}, \mathrm{SiC}$, and natural nanotubes. But these are not in wide use yet. It is also possible and likely that other types of compound nanotubes and hybrid nanotubes may be discovered or designed in the future. It is worthwhile and necessary to continue to invest in nanotube materials 
development to compete successfully economically internationally, and to sustain our environment, advance our engineering designs, and to improve our health care. Finally, the authors apologize in advance if they inadvertently missed listing in this article any companies that are commercializing nanotube sheet and yarn. Readers are also encouraged to perform their own survey to stay abreast of the field as the technology is developing now at the speed of industry.

\section{References}

[1] Mark J. Schulz, Vesselin Shanov, John Yin, Marc Cahay, editors, Nanotube Superfiber Materials, Science, Manufacturing, Commercialization, $2^{\text {nd }}$ Edition, Elsevier, March, 2019.

[2] Patent Pending: Methods of Manufacturing Carbon Nanotube (CNT) Hybrid Sheet and Yarn by Gas Phase Assembly, and CNTHybrid Materials, Mark Schulz, Vianessa $\mathrm{Ng}$, Guangfeng Hou, and others application \#: PCT/US2018/019427, February 2018.

[3] G. Hou et al., Gas-phase pyrolysis synthesis of carbon nanotubes at high temperature, Mater. Des., vol. 132, pp. 112-118, Oct. 2017.

[4] F. L. Deepak, N. S. John, A. Govindaraj, G. U. Kulkarni, and C. N. R. Rao, Nature and electronic properties of $Y$-junctions in CNTs and $N$-doped CNTs obtained by the pyrolysis of organometallic precursors, Chem. Phys. Lett., vol. 411, no. 4-6, pp. 468-473, Aug. 2005.

[5] R. Sen, A. Govindaraj, and C. N. R. Rao, Carbon nanotubes by the metallocene route, Chem. Phys. Lett., vol. 267, no. 3-4, pp. 276-280, Mar. 1997.

[6] Lee Weller, Fiona R. Smail, James A. Elliott, Alan H. Windle, Adam M. Boies, Simone Hochgre, Mapping the parameter space for direct-spun carbon nanotube aerogels, Carbon 146 (2019) 789-812.

[7] D. Conroy, A. Moisala, S. Cardoso, A. Windle, and J. Davidson, Carbon nanotube reactor: Ferrocene decomposition, iron particle growth, nanotube aggregation, and scale-up, Chem. Eng. Sci., vol. 65, no. 10, pp. 2965-2977, May 2010.
[8] N. Mohammadian, S. Ghoreishi, S. Hafeziyeh, S. Saeidi, and D. Dionysiou, Optimization of Synthesis Conditions of Carbon Nanotubes via Ultrasonic-Assisted Floating Catalyst Deposition Using Response Surface Methodology, Nanomaterials, vol. 8, no. 5, p. 316, May 2018.

[9] General Nano Company, https://www.veelotech.com/

[10] Nanocomp Technologies, http://www.miralon.com/, http://www.miralon.com/health-safety, https://www.huntsman.com/products/detail/ 344/miralon

[11] American Boronite Company, http://www.boronite.com/\#!/home

[12] TE Connectivity Company, https://www.te.com/usaen/industries/aerospace/insights/carbonnanotube-technology.html

[13] Lintec Company, http://www.lintecglobal.com/; http://www.lintec-nstc.com/

[14] J. Sullivan, M. Schulz, K. Vemaganti, A. Bhattacharya, B.J. Jetter, V. Shanov, N. Alvarez, Jay Kim, Carbon Nanotube Fabric Cooling System for Firefighters and First Responders: Modeling and Simulation, Journal of Fiber Bioengineering and Informatics, Journal of Fiber Bioengineering and Informatics 8:1 (2015) 1-12, doi:10.3993/jfbi03201501.

[15] Patent Pending: Carbon Nanotube Hybrid Material Fabric, Composite Fabric, and Personal Protective Apparel and Equipment, Mark Schulz, Vianessa $\mathrm{Ng}$, Guangfeng Hou, et al, 10738-620 PCT, July 2018.

[16] Devika Chauhan, Chenhao Xu, Daniel Chen, Ashley Kubley, Brooke Brandewie, Guangfeng Hou, Weifeng Li, Vianessa Ng, Massoud Rabiee, Marc Cahay, Woo Kyun Kim, Sumeet Chaudhary, Khwaja Moinuddin, Michael Paine, Richard Kleismit, David Mast, Surendra Devarakonda, SangYoung Son, Mark J. Schulz, Vesselin N. Shanov, Introduction to Carbon Nanotube Hybrid Textiles, Journal of Textile Science \& Fashion Technology, 1(5): 2019. JTSFT.MS.ID.000525.

[17] Daniel Chen, Devika Chauhan, 
Guangfeng Hou, Weifeng Li, Vianessa Ng, Massoud Rabiee, Marc Cahay, Woo Kyun Kim, Sumeet Chaudhary, Khwaja Moinuddin, Michael Paine, Chenhao Xu, Megha Chitranshi, Anuptha Pujari, Richard Kleismit, David Mast, Vesselin N. Shanov, Mark J. Schulz, Introduction to Carbon Hybrid Materials, Nanotechnology Materials and Devices Workshop, May 21, 2018, University of Cincinnati, http://nmdworkshop.utcdayton.com/.

[18] Y. Song et al., Carbon nanotube sheet reinforced laminated composites, in Proc. of the American Society for Composites: 31st Technical Conf., 2016.

[19] J. L. Abot et al., Delamination detection with carbon nanotube thread in self-sensing composite materials, Compos. Sci. Technol., vol. 70, no. 7, pp. 1113-1119, Jul. 2010.

[20] J. L. Abot, M. J. Schulz, Y. Song, S. Medikonda, and N. Rooy, Novel distributed strain sensing in polymeric materials, Smart Mater. Struct., vol. 19, no. 8, p. 085007 , Aug. 2010.

[21] S. D. Keller, A. I. Zaghloul, V. Shanov, M. J. Schulz, D. B. Mast, and N. T. Alvarez, Radiation performance of polarization selective carbon nanotube sheet patch antennas, IEEE Trans. Antennas Propag., vol. 62, no. 1, pp. 48-55, Jan. 2014.

[22] E. Amram Bengio et al., High-efficiency carbon nanotube thread antennas, Appl. Phys. Lett., vol. 111, no. 16, p. 163109, Oct. 2017.

[23] I.Puchades, J. E. Rossi, C. D. Cress, E. Naglich, and B. J. Landi, Carbon nanotube thin-film antennas, ACS Appl. Mater. Interfaces, vol. 8, no. 32, pp. 20986-20992, Aug. 2016.

[24] L. Sun, X. Wang, Y. Wang, and Q. Zhang, Roles of carbon nanotubes in novel energy storage devices, Carbon N. Y., vol. 122, pp. 462-474, Oct. 2017.

[25] Jae-Hak Kim, K. H. Lee, L. J. Overzet, and G. S. Lee, Energy storage devices using spinnable CNT sheets, 2011 IEEE Nanotechnology Materials and Devices Conference, 2011, pp. 45-49.

[26] G. $\mathrm{Wu}$ et al., High-performance supercapacitors based on electrochemicalinduced vertical-aligned carbon nanotubes and polyaniline nanocomposite electrodes, Sci. Rep., V7, no.1, p. 43676, Dec. 2017.

[27] Stafiej A., Pyrzynska K. Adsorption of heavy metal ions with carbon nanotubes. Seprartion and Purification Technology 2007; 58:49-52.

[28] Zarghami S., Tofighy M.A., Mohammadi T. Adsorption of zinc and lead ions from aqueous solutions using chitosan/polyvinyl alcohol membrane incorporated via acid-functionalized carbon nanotubes. Journal of Dispersion Science and Technology 2015; 36:1793-1798.

[29] Chen Y.C., Lo S.L., Luo J. Pb(II) adsorption capacity and behavior of titanate nanotubes made by microwave hydrothermal method. Colloids Surf. A 2010; 361:126-131.

[30] Li J., Chen S., Sheng G., Hu J., Tan X., Wang X. Effect of surfactants on Pb(II) adsorption from aqueous solution using oxidized multiwall carbon nanotubes. Chem. Eng. J. 2011; 166:551-559.

[31] Savage N., Diallo M.S. Nanomaterials for water purification. J Nanopart Res 2005; 7:331-42.

[32] Li Y.H., Di Z., Ding J., Wu D., Luan Z., Zhu Y. Adsorption thermodynamic, kinetic and desorption studies of Pb2+on carbon nanotubes. Water Res 2005; 39:605-9.

[33] Ihsanullah, Aamir A., Adnan M.A., Tahar L., Mohammed J.A., Mustafa S.N., Majeda K., Muataz A.A. Heavy metal removal from aqueous solution by advanced carbon nanotubes: critical review of adsorption applications. Separation and Purification Technology 2016; 157: 141161.

[34] Di Z.C., Li Y.H., Luan Z.K., Liang J. Adsorption of chromium (VI) ions from water by carbon nanotubes, Adsorpt. Sci. Technol. 2004; 22:467-474.

[35] Wang H.J., Zhou A.L., Peng F., Yu H., Chen L.F. Adsorption characteristic of acidified carbon nanotubes for heavy metal $\mathrm{Pb}(\mathrm{II})$ in aqueous solution, Mater.Sci. Eng. A. 2007; 466:201-206

[36] Ihsanullah, Khaldi F.A.A., Abusharkh B., Khaled M., Atieh M.A., Nasser M.S., Laoui T., Agarwal S., Tyagi I., Gupta V.K. Adsorptive removal of cadmium(II) ions 
from liquid phase using acid modified carbon-based adsorbents, J. Mol. Liq. 2015; 204:255-263.

[37] Rao G.P., Lu C., Su F. Sorption of divalent metal ions from aqueous solution by carbon nanotubes: a review, Sep. Purif. Technol. 2007; 58:224-231.

[38] Pyrhönen, J., Montonen, J., Lindh, P., Vauterin, J., \& Otto, M. (2015). Replacing copper with new carbon nanomaterials in electrical machine windings. International Review of Electrical Engineering (IREE).

[39] E.Dujardin, T. W. Ebbesen, H. Hiura, K. Tanigaki, Capillarity and Wetting of Carbon Nanotubes, Science 23 Sep 1994: Vol. 265, Issue 5180, pp. 1850-1852, DOI: 10.1126/science.265.5180.1850.

[40] Mrityunjay Singh, Tatsuki Ohji, Rajiv Asthana, Sanjay Mathur, Ceramic integration and joining technologies: From Macro to Nanoscale, 1st Edition, WileyAmerican Ceramic Society, (2012).

[41] T.W Ebbesen, Wetting, filling and decorating carbon nanotubes, Journal of Physics and Chemistry of Solids, V 57, Issues 6-8, June-August 1996, Pages 951955.

[42] Michael B. Jakubinek, Behnam Ashrafi, Yadienka Martinez-Rubi, Jingwen Guan, Meysam Rahmat, Keun Su Kim, Stephane Denommee, Christopher T. Kingston, Benoit Simard, CHAPTER 5, Boron Nitride Nanotube Composites and Applications, in Nanotube Superfiber Materials, Science, Manufacturing, Commercialization, $2^{\text {nd }}$ Edition, 2019.

[43] Amanda L. Tiano, Cheol Park, Joseph W. Lee, Hoa H. Luong, Luke J. Gibbons, Sang-Hyon Chu, Samantha I. Applin, Peter Gnoffo, Sharon Lowther, Hyun Jung Kim, Paul M. Danehy, Jennifer A. Inman, Stephen B. Jones, Jin Ho Kang, Godfrey Sauti, Sheila A. Thibeault, Vesselin Yamakov, Kristopher E. Wise, Ji Su, Catharine C. Fay, Boron Nitride Nanotube: Synthesis and Applications. NASA report, https://ntrs.nasa.gov/search.jsp?R=20140004 051 2019-04-10T12:24:12+00:00Z.

[44] BNNT Company, http://www.bnnt.com [45] Dexmat Company; https://dexmat.com/
[46] Fujitsu
Research,

https://www.fujitsu.com/global/about/resour ces/news/press-releases/2017/1130-01.html

[47] Naieel http://www.naieel.com/naieel/

[48] http://www.nanomech.com/nanoinnovations/markets-applications/

[49] Nanointegris Company, http://nanointegris.com/our-products/boronnitride-nanotubes-purified-bnnt-p/;

[50] Q-Flo Company, https://www.qflo.com/; Based on technology from University of Cambridge, UK

[51] Tekna Company, http://www.tekna.com; http://www.tekna.com/boron-nitridenanotubes

[52] Weifeng Li, Chaminda Jayasinghe, Vesselin Shanov and Mark Schulz, Spinning Carbon Nanotube Nanothread under a Scanning Electron Microscope, Materials 2011, 4, 1519-1527, doi:10.3390/ma4091519.

[53] Yunxiang Bai, Rufan Zhang, Xuan Ye, Zhenxing Zhu, Huanhuan Xie, Boyuan Shen, Dali Cai, Bofei Liu, Chenxi Zhang, Zhao Jia, Shenli Zhang, Xide Li \& Fei Wei, Carbon nanotube bundles with tensile strength over $80 \quad G P a, \quad$ Nature Nanotechnology, volume 13, pages 589-595 (2018).

[54] Chengmin Jiang, Avishek Saha, Changsheng Xiang, Colin C. Young, James M. Tour, Matteo Pasquali, Angel A. Mart. Increased Solubility, Liquid-Crystalline Phase, and Selective Functionalization of Single-Walled Carbon Nanotube Polyelectrolyte Dispersions. ACS Nano, 2013; 130416090924009 DOI: $10.1021 / \mathrm{nn} 4011544$.

[55] Kalay, S.; Yilmaz, Z.; Sen, O.; Emanet, M.; Kazanc, E.; Çulha, M. Beilstein, Synthesis of boron nitride nanotubes and their applications, J. Nanotechnol. 2015, 6, 84-102. doi:10.3762/bjnano.6.9.

[56] https://www.nano.gov/about-nni/what

[57] Megha Chitranshi, Devika Chauhan, Ashley Kubley, Anuptha Pujari, Chenhao 
$\mathrm{Xu}$, Daniel Chen, Sumeet Chaudhary, Guangfeng Hou, Gregory Bell, Brooke Brandewie, Rutvik Kaneria, Ronald Hudepohl, Mark J Schulz, Pioneering carbon nanotube textile engineering \& fashion technology. J Textile Eng Fashion Technol. 2019;5(2):89-92.

[58] https://www.uc.edu/president/communic ations/news/2018/next-lives-here-

launch.html

[59] https://www.nsf.gov/news/special_repor ts/i-corps/

[60] Rice Workshop, http://guadalupe.rice.edu/

[61] Nanotechnology Materials and Devices (NMD) Workshop, https://nmdworkshop.org/

[62] Michigan State, International Conference on the Science and Application of Nanotubes, http://nanotube.msu.edu/

[63] International Nanotechnology Exhibition and Conference, Japan, https://www.nanotechexpo.jp/,

[64] Nanoinnovations Conference, http://www.nanoinnovation2019.eu/.

[65] https://research.wsu.edu/researchinitiatives/smart-systems/materials/

[66] http://cem.osu.edu/

[67] https://www.springer.com/materials/jour nal/42247

[68] https://www.nsf.gov/awardsearch/show Award?AWD_ID=1708448\&HistoricalAwa rds $=$ false

[69] https://research.shanghai.nyu.edu/center s-and-institutes/physics/events/emergentquantum-materials-and-phenomena-underhigh-pressure

[70] https://www.tandfonline.com/doi/full/10 .1088/1468-6996/13/4/043001

[71] https://www.researchgate.net/publicatio n/292782699_Emergent_Futures_Nanotecho logy_and_Emergent_Materials_in_Architect ure

[72] https://gow.epsrc.ukri.org/NGBOViewG rant.aspx?GrantRef=EP/I004475/1

[73] https://emergingmaterials.materialsconfe rences.com/
[74] https://science.energy.gov/bes/efrc/histo ry/grand-challenges/

[75] https://www.amazon.com/Made-

Measure-Materials-21st-

Century/dp/0691009759

[76] Philip Ball, Made to Measure: New Materials for the 21st Century, Princeton University Press, 1997.

[77] https://www.nanowerk.com/nanocatalog /Single-

walled_carbon_nanotubes/Metallic_Single-

Walled_Carbon_Nanotubes/details/5101\#clo se. https://ad-nanotech.com/

[78] Sangsu Lee, Jeong-Seok Nam, Jiye Han, Qiang Zhang, Esko I. Kauppinen, and Il Jeon. Carbon Nanotube Mask Filters and Their Hydrophobic Barrier and Hyperthermic Antiviral Effects on SARSCoV-2. ACS Appl. Nano Mater, July, 2021. https://doi.org/10.1021/acsanm.1c01386 Read.

[79] Jyoti Prakash, Anusree Dey, Sheetal Uppal, Rajath Alexander, Amit Kaushal, Hari Sharan Misra, Kinshuk Dasgupta. Label-free rapid electrochemical detection of DNA hybridization using ultrasensitive standalone CNT aerogel biosensor. Biosensors and Bioelectronics, Volume 191, 1 November 2021, 113480.

[80] NIOSH Report. Current Intelligence Bulletin 65: Occupational Exposure to Carbon Nanotubes and Nanofibers. https://www.cdc.gov/niosh/docs/2013-145/.

[81] Stefaniak, Aleksandr B. (2017).

Principal Metrics and Instrumentation for

Characterization of Engineered

Nanomaterials. In Mansfield, Elisabeth;

Kaiser, Debra L.; Fujita, Daisuke; Van de

Voorde, Marcel (eds.). Metrology and

Standardization of Nanotechnology. Wiley-

VCH Verlag. pp. 151-174.

doi:10.1002/9783527800308.ch8. ISBN 9783527800308.

[82] Wikipedia, https://en.wikipedia.org/wiki/Carbon_nanotu be\#cite_note-:02-87.

[83] https://www.nanowerk.com/carbon_nan otube_manufacturers_and_suppliers.php.

[84] https://www.nano.gov/node/1340. 
Contribution of Individual Authors to the Creation of a Scientific Article (Ghostwriting Policy) Author Contributions:

The authors contributed equally to this paper. Mark J. Schulz and Sung Yong Kim synthesized the nanotube materials described in the paper. Ashley Kubley fabricated the glove and led the textiles development described in the paper. David Mast and Vesselin Shanov helped to develop the specific synthesis process used for manufacturing the nanotube materials described in this paper.

\section{Sources of Funding for Research} Presented in a Scientific Article or Scientific Article Itself

This research study was partially supported by the National Institute for Occupational Safety and Health Pilot Research Project Training Program of the University of Cincinnati Education and Research Center Grant \#T42/OH008432. This research was also supported by the NSF ERC EEC-0812348 and UCTAC Seed Grant under ESP TECH 15-0160.

\section{Creative Commons Attribution License}

\section{0 (Attribution 4.0 International, CC BY}

4.0)

This article is published under the terms of the Creative Commons Attribution License 4.0

https://creativecommons.org/licenses/by/4.0/dee d.en US 